\title{
COMPARISON OF PUBLIC AND PRIVATE SECONDARY SCHOOL TEACHERS' PERCEPTIONS ABOUT CREATIVITY AS A CULTIVATED SKILL IN THE CLASS ROOM PRACTICES
}

\author{
Afsar Sultana \\ Ph.D. Scholar, \\ Department of Education, Iqra University Karachi, \\ Sindh, Pakistan \\ Email: sultana58@live.com \\ Anjum Bano Kazimi \\ Professor, \\ Department of Education, Iqra University Karachi, \\ Sindh, Pakistan \\ Email: anjum.bano@iuk.edu.pk
}

\begin{abstract}
The research examines and compares public and private secondary school teachers' perceptions about creativity as a skill that can be cultivated in their class room practices. The researcher adopted PBA, a psychological model of professional behavior analysis for analyzing professionals' perception. Any professional expert's positive perception is essential regarding the strategies, to handle the task properly and achieve its maximum objectives. In the present study secondary school teachers of Malir district were taken as population of the study and were divided into two clusters; public and private. For selecting the sample of 560 sizes, each sub group of the sample remained equal by using probability technique. All the clusters were collected randomly. Mixed Method was the adopted research method; quantitative analysis contributes $80 \%$ and qualitative analysis contributes $20 \%$. Survey was the research design to collect the data. Close ended questionnaire was developed for collecting quantitative data. In-depth Interview was developed for collecting qualitative data. Independent sample t-test was used to compare the groups quantitatively and thematic analysis for qualitatively. The data triangulation determined the degree of strength of their perceptions. Obtained findings depict that private school teachers' perceptions are stronger than public school teacher regarding the issue.
\end{abstract}




\section{KEYWORDS}

Creativity, Creative teacher, Creative student, Creative school

\section{INTRODUCTION}

Creativity in education is a foundation of inspiration for teachers and students. Itprovides source through which a very important basis is provided to a traditional and an outdated method of teaching. It's an irony that we are not able to provide a better system of Education in Pakistan even after seven decades. As a developing nation Pakistan needs to make changes in its system of education too because for the last seventy- two years, we have been following the same pattern of methodologies of teaching in schools colleges and universities. We could not have good engineers, doctors and other professionals. We are also missing the world wide acceptance of our system of education. Activity based education is missing (quality of education is not up to the mark, teachers are not able to teach properly (Education policy2017)

Some of the researchers and scholars' opinions unveil thatthere has been a remarkable rise in the number of schools in Pakistan over the last few decades but the quality has dropped drastically and the schools failed to meet the least amount quality criteria especially public schools due to rote learning and traditional methods of teaching. There is lack of instructional techniques, lack of originality, novelty innovation and newness. Most of the teachers are not trained to teach. It's one of the factors that teachers don't know how to help their students. After passing through rote learning, students do not outshine when they join higher education. Rote learning and memorization should be replaced with creative skills and the system of education should be made supportive for all students.

Dr. Shaheen (2010, p.166) conducted a research in which one thousand and eight students participated. With the help of survey she wants to know whether the system of Pakistan is in a position to provide a creative system of Education to our students or not. Her study finds that the curriculum of Pakistan's educational system does little to encourage students.

Teachers of English can use creative teaching as a strategy to develop language skills alongside imparting the prescribed curriculum. Right mix of creativity with curriculum makes lessons more interesting and interactive, helps students to be inventive. As it is indirectly related to sensory cognitive, emotional, motor and social developments, these developments are improved and the students apply them in their daily lives. Students become good communicators; they love to have creative activities with their curriculum without the pressure of learning. Conventional teaching methods do not give them goodness, satisfaction and happiness. They want to learn freely without any boundaries. Hands -on learning, open ended questions, brainstorming sessions and 
other activities reduce their tension and anxiety and they prepare well to excel in exams.

\section{Creative Skills}

Creative skills are expansively prominent as the best way for students to survive with the ever increasing challenges of life. Creativity is measured as one of the most important character in human beings. Tsai(2012, p.84) asserts that creativity is perceived as the tendency to be new and unique, distinct and apart. Yong Shao(2019, p.15-17)states that creativity is a result of human consideration that operates on a set of accessible representations concepts, items, signs, regulations or ideas. Every nation needs creative thinkers in the form of scientists, engineers, doctors, artists, writers, educators etc. Lucas ( 2019, p.11-25) stresses that creativity plays a vital role at an individual as well as at a group level.According to the author the entire World is very much provoked and inspired by the unusual intellect or we may call it creativity and believe that it should be part of syllabi of all schools in England as well as in other countries..Alberto( 2019) Claims that creativity helps thinking in new, unique, innovative and practical ways and shows itself in different context. Every next second we can confront a problem which might require unique, out of the box solutions. Creativity is perceived as an important tool for the advancement and productivity in today's world of competition.

\section{Adopted Model}

PBA model analyzes teachers' practice of teaching in the secondary school to foster learners' creativity. This model explores three dimension of teaching practices those are; Perception, Believe in specific and relevant strategies and adopting the believed teaching strategies. The adopted model is derived from the models used for examining professional attitude to observe the degree of adequacy of a professional expertise with the assigned task. Firstly, this model assumes that professional expert handles the assigned task properly and achieves its utmost objectives when he or she has positive perception for it as well as perceives it beneficial and progressive for the organization or masses.

\section{LITERATUREREVIEW}

Creativity involves innovation and generation of new ideas. It is quite evident that the main pillar of progressive nations is creativity. In Pakistan the question of creative work in different sectors is quite debatable. Huge talent goes to dustbin because of the lack of quality education and creativity. If only the state focused on these aspects, one would have had different results. The researcher guesses students are very creative. They just need a platform to explore themselves. They are skillful and creative in every aspect. They have amazing ideas to overcome the problems. 
Dr. Aijaz (2018) in his book "Learning Achievement in Primary Schools of Pakistan states that there are limitless numbers of schools in Pakistan in urban and rural areas, but the Government of Pakistan has failed to provide creative facilities due to untrained teachers and traditional methods of teaching. He also mentions some other reasons that are creating hurdles in providing creativity among students of Pakistan.

Dr. Aijaz (2018) in his book "Learning Achievement in Primary Schools of Pakistan" states that there are limitless numbers of schools in Pakistan in urban and rural areas, but the Government of Pakistan has failed to provide creative facilities due to untrained teachers and traditional methods of teaching. He also mentions some other reasons that are creating hurdles in providing creativity among students of Pakistan.

According to Yu-ChengChien, Ming-ChiLiu, Ting -Ting Wu (2020), creativity not only affects originality and development but also increases the expediency of thoughts and numberless dreams of human beings. Accordingly creativity helps in promoting action which in return is beneficial for the promotion of education.

Danielle E.Kaplan (2019) claims that creativity is very important to modernization uniqueness and nourishment of the students. His research from beginning to the end was particularly for the teachers' training programme. Brown \& Wilson (2019) considered creativity as a developmental capacity and believed that pedagogic practices can be polished to meet the hopes and needs of existing practitioners and educational contexts.

Boden (2019) states that creativity generates new concepts and ideas that can be easily understood; clear to the mind and are also worthwhile. Since schools and colleges are said to be the exact places for enhancing and creating creativity among students. The author points out that educational institutions offer chances for interaction and sharing of ideas. They are considered the horizon of novelty as creativity only depends upon socialization.

Panel Elisa Kupers (Kupers, 2020, p.1-7)understands creativity as essentially social in the context of education as personified and entrenched between student and teacher relations. Creativity makes students involved in their studies fully. Mohnen \&Ostermaier, et al (2013,520-526)suggest that creativity develops and strengthens teaching in performing arts and sports. They attain higher creative qualities in business management and marketing. In their opinion creativity is the source of intrinsic information. It increases the performance of the students.

John D Medaglia, FBetzel,SharonLThompson -Schill, Jiang Qiu (Yoed N Kenett, 2018, p.79-90) believe that creativity and intelligence are elevated cognitive constructs and involve multifaceted and numerous processes .Panel Elisa 
Kupers(Kupers, Creativity in interaction: the dynamics of teacher-student interactions during a musical composition task, 2020, pp.1-7) inform how teachers make possible the progress of creativity during music and art classes and also how creativity emerges interface between teachers and students.

Bryant, S. L (1995, pp.269) points out that creativity aims to guide students and equips them out of the mind-set of the Knowledge. It helps them in novelty and Creativity. He indicates potential for students to work professionally. Creativity focuses on the benefits, for individuals and society.

Batchelor (2013, p.3) describes that teaching can be categorized in different kinds but the teaching style which provides upgrading to the students or enhances the quality of education is well thought-out the best teaching style by the stakeholders. In other words it is accessible, challenging, balanced, and rational for every student; creativity maintains novelty and financial growth in every division of the world. They suggest that teaching is the best teaching that promotes creativity in teaching learning environment.

Cristian Mejia and Yuya (2021) emphasize the need of the computational methods. They further expose the history of creativity, psychology of creativity cultural psychology and variety of topics with this help. Lastly in conclusion they converse how computational methods help develop different research fields of creativity and how it helps policy makers and curriculum developers boost creativity in schools among students.

Sylvain Fleury Aurelien Agnes Rishi Vanukurn Emma Goumillout Nicolas and Simon Richir (2020) studied the special effects of visual movement on creativity and noticed that physical activity arouses certain cognitive functions and creativity increases from the awareness of movement.

Bilal points out that the teachers of Pakistani schools have limited word bank; are not trained to use free flow of ideas: cannot usually weave words and ideas together to form associations. Most of the times they reproduce memorized contents without internalizing meaning. Vazir \& Ismail (2009, p.302) investigate how a teacher chooses an inappropriate methodology to teach creative writing skill to young children. According to them Pakistani educational system is based on cramming. This cramming system is detrimental to student creativity. However situation seems to be quite different in modern private educational system. Students are encouraged to be more creative in their thinking." Jabeen \& Akhtar (2013 ,pp. 1-10) lament that the system of our education does not provide any help regarding novelty; instead it provides a system that generates more complex communication system for the students. The 
students lack communicative skill due to customary methods and some are the weaknesses of teachers too. H.Khan (2012, pp.57-67) discloses that teachers do not give any importance to those methods that enhance the creative abilities of students instead they use traditional methods of teaching. Bilal (2013,P.1) criticizes that creativity is being ignored in Pakistan. She praises that high profile schools are trying their level best to promote creativity to some extent but simultaneously expresses sorrow that public and low profile schools are not able to provide any chances to students to enhance their creative abilities.

\section{RESEARCH OBJECTIVES}

1. To explore the degree of strength of perception of English language teachers of public secondary schools in district Malir

2. To explore the degree of strength of perception of English language teachers of private secondary schools in district Malir

3. To compare the degree of strength of perception of public and private English language teachers of secondary schools in district Malir

\section{RESEARCH QUESTION}

1. What perceptions do the teachers of public and private schools have about creativity in their class room practices?

\section{RESEARCH HYPOTHESES}

1. There is significant difference in the perceptions of private and public English language teachers about creativity at secondary Schools

\section{RESEARCH METHODOLOGY}

Researcher took Secondary school English language teachers of Malir district as population of the study. She took 560 Secondary school English language teachers as a sample .She adopted cluster random sampling to divide into two clusters; public and private. For selecting the sample, each cluster of the sample remained equal in size of 280 by using probability technique. All the clusters were collected randomly. Researcher adopted Mixed Method in which quantitative analysis contributes $80 \%$ and qualitative analysis contributes $20 \%$. She selected Survey as the research design to collect the data. She developed close ended questionnaire for collecting quantitative data regarding the teachers' perceptions. She conducted In-depth Interview for collecting their own words regarding the issue to understand the themes of their views qualitatively. For qualitative data she developed probing questions for in-depth interviews. When she became saturated by the responses of respondent, she had gone to next respondent on identification of the previous respondent. For qualitative purpose she adopted snowball sampling technique to find the respondents. The items of all the instruments were drawn from the relevant content field in consultation with the experts 
and review of related literature. This procedure ensured the content validity of the questionnaire. Instruments contained 20 items. Internal consistency for questionnaire for teachers was found to be 0.73 . Thematic analysis was used to compare the groups qualitatively and Independent sample t-test for quantitatively. This test ideally compares the two groups' means to report whether their scores are similar or different. This also highlights insignificant or significant results respectively. The two types of data were combined in the end to see the association and connection in teachers' perspectives about creativity.

\section{Independent Samples Test}

\begin{tabular}{|c|c|c|c|c|c|c|c|c|c|}
\hline \multirow[b]{2}{*}{ Hypothesis } & \multicolumn{2}{|c|}{$\begin{array}{c}\text { Levene's Test } \\
\text { for Equality } \\
\text { of Variances }\end{array}$} & \multicolumn{7}{|c|}{ t-test for Equality of Means } \\
\hline & $\mathbf{F}$ & Sig. & t & Df & $\begin{array}{l}\text { Sig. } \\
(2- \\
\text { tailed })\end{array}$ & $\begin{array}{c}\text { Mean } \\
\text { Difference }\end{array}$ & $\begin{array}{l}\text { Std. Error } \\
\text { Difference }\end{array}$ & $\begin{array}{r}95 \% \text { Co } \\
\text { Interva } \\
\text { Diffe }\end{array}$ & $\begin{array}{l}\text { fidence } \\
\text { of the } \\
\text { nce }\end{array}$ \\
\hline $\begin{array}{l}\text { 1. There is } \\
\text { significant } \\
\text { difference } \\
\text { in } \\
\text { perception } \\
\text { of private } \\
\text { and public } \\
\text { school } \\
\text { teachers } \\
\text { about } \\
\text { creativity }\end{array}$ & 0.822 & 0.365 & 195.437 & 558 & 0 & 15.80357 & 0.08086 & Lower & Upper \\
\hline
\end{tabular}

The table represents results of independent sample t-test for testing Hypothesis, "There is significant difference in perception of private and public school teachers about creativity The hypothesis was framed to compare the perceptions of private School English Language Teachers and public school teachers about creativity as a cultivated skill".

In this regard, Description of the hypothesis is in column 1. The table contains Levene's test for equality of variance in columns 2 and 3. The Levene's test for equality of variance depicts that both groups have equal variance and considered similar to be compared. T-value is given in column 4. Degree of freedom is in column 5. Value of significance is in column 4. Mean difference is in the column 6. Mean difference is in column 7. Standard deviation is in the column 8. Standard Error of Mean is in column 9. Interval of the difference with $95 \%$ confidence is in the columns 10 and 11. Positive mean difference 15.80357 (highlighted value in column 7 depicts that obtained mean for private school teachers is greater than the mean for public school teachers and it explains that the alternative hypothesis is accepted. The 
Positive t-value in column 4 also supports the acceptance of alternative hypothesis and $\mathrm{P}$ - Value (highlighted value in column 4) is 0.00 expresses that the findings are significant enough to accept the inference of hidden meanings so the null hypothesis has been rejected and the alternative hypothesis "Private school teachers are different from public school teachers in perceiving that creativity is a cultivated skill" has been accepted.

\section{FINDINGS \& DISCUSSION}

Unlike private school teachers, public school teachers were found to be mechanical and robot like in their treatment of teaching lessons. Unfortunately most of the teachers, from public schools seemed to have very limited vocabulary themselves and thus were not in a position to encourage the students to use new words. They occasionally used good words, but could not use them express their creativity. Teachers in private schools made powerful use of senses through imagery. According to them, they made students visualize and communicate powerful images into words of eloquence. Private teachers were familiar with the use of visual, auditory and tactile images and scaffold the students, how to use senses to create images; how to put words in the form of people and actions to achieve their full force. Private school teachers enthusiastically showing preferences for creativity associated it with innovation and discovery. Their responses in narrative commentary and their participations observed during interview revealed that they enjoyed activities; projects and assignment that afforded them contact with real life situations.

They were familiar with the use of figures of speech such as metaphor, simile, comparison, alliteration, personification and illusion; they taught the same to the students effectively using several examples and relating this real-life experience. Students enjoyed in the company of the teachers.

A marked difference was observed in the professional background of the teachers of the two streams and in the way they perceived themselves and school to be responsible for the development of creativity. Though both streams of teachers' were subject specialists, teachers from private schools were found to be more active and responsible.

A considerable difference was observed in the difference related to teachers' sensitivity to the issue on the basis of their experience. Unlike quantitative analysis which highlights a significant difference, qualitative shows a moderate difference in teachers handling of situations in classroom and in perceiving the importance of the issue on the basis of experience.

Surprisingly all public school teachers though trained could not impress the researcher in the way they planned, executed and assessed their lessons and in the way treated the 
assignments given in the class with a routine and mechanical attitude. Private school teachers on the other hand seemed accountable for how they performed in the class. They loved using figurative language and participating in projects and role plays aesthetically when guided and supported their students. Here researcher considers it noteworthy to mention her own experience with these teachers. During data collection process, researcher had to obtain teachers' responses on creativity in the form of narrative commentaries. This process started as a general discussion, but teachers were not getting the point. They thought they had to write essays on creativity but researcher was interested in gauging lived experiences regarding their perceived creativity level and creativity fostering practices in the classroom. In order to help them understand this, the researcher shared her own experience as a child, with a creative teacher she still remembered and this triggered favorable response. Teachers laughing, enjoying and simultaneously sharing their interesting experiences with their friends wrote the narratives, and said in the end that this was the first time they had described their creative selves so creatively. Their responses in the end made the researcher feel proud of them.

As the interviews highlight that teachers associate creativity with innovation and discovery, they should be given opportunities for maximum participation through projects, creative assignments, and interesting activities. Through the convergence of qualitative and quantitative data the researcher comes to know that no difference is found in teachers' perceptions on schools but a noticeable dissimilarity is observed in the qualified background of the teachers of the two streams' role in nurturing creativity on the basis of methodologies.

On the basis of the above findings, the paper will lend insight to policy planners, researchers, and national curriculum developers in Pakistan to increase programms that can act in response to the creative requirements and desires of the students. The researcher reports some successes in the implementation of creativity in the private schools but it remains foreign to all public schools. This implies that creative concepts have not been cognitively internalized and learners are very much confused and perplexed outside and inside class rooms therefore it is necessary to include creative skill in everyday life experiences.

The researcher found that teachers who work in the school run by private management perceive more strongly than teachers who work in the school run by government bodies of management about creativity as a cultivated skill. More researches are required to explore the phenomena but a more simple cause was seemed among them for the issue. Government doesn't provide them any opportunity to upgrade or update their knowledge. 
There is a need to bring an effective pedagogy in our educational system of Pakistan. A research is needed for documenting the impact of creativity on students' learning. This research would helpful for teachers in the development of teaching learning process. This study would provide good reasons to the implementation of creativity

based learning method within and across the schools.

\section{RECOMMENDATIONS}

In the light of the above mentioned findings, the study recommends the need for supporting rich and supporting classroom and school environments with teachers showing trust in their selves and students' creative ability. In Pakistan, students are not given open hand by the teachers or parents. They are restricted to certain limits but many learning institutions try to give exposure to their students and want them to be creative.

Teachers should cultivate creativity by creating conducive environments which afford first hand touch of the concepts taught in the class; and by using motivational and reenforcement strategies such as assigning marks, remarks, putting up students' work on the notice-board, giving individual feedback, awarding most creative work of the week awards, and appreciating students' work in front of their peers.

Teachers as the most important literacy facilitators must be trained to explore an array of more effective, engaging and exciting writing tasks that can spur students' interest in creative skills. It is also the duty of the heads to appreciate those teachers daily who are dedicated and imparting creative skills among students. Parents should be taken in confidence

Parents are requested to develop children's creativity while at home by providing them a safe environment where they are allowed to exercise self-sufficiency and take risks. A home should be a supportive place for them. Creativity of parents is more important part of their child.

At the present time a very few parents are using different ways to make their child creative. They allow their children to explore their ideas and do what they want because this is need for them to go ahead to achieve goals in life.

\section{REFERENCES}

Aijaz, S. M. (2001,pp .105-154). Learning achievement in primary schools of Pakistan: a quest for quality education. Islamabad: UNESCO.

Alberto, Andrew Rogers, Shannon K.Pinegar and Yana vative, and 2019, p.58-60, 
Workspace, 07 July 2021 https://doi.org/10.1111/caim.12453

Disorder Does Not Influence Creativity a nd Executive FunctionsBatchelor, K. E. (2013, p.3)

Boden, M. A. (2007,pp.83-96). Creativity in a nutshell. Think, 5(15)

Brown, M., \& Wilson, C. (2015, pp.134). Conformity, deformity, and reformity: considering the domain-idiolect creativity dynamic. KIE Conference Publications.

Bryant, S. L. (2014,pp.4). Queensland teachers' conceptions of creativity: A phenomenographic investigation.Cristian Mejia, Major and recent trends in creativity research: An overview of the field with the aid of computational methods

Danielle,, E.Kaplan, 2019, pp.140-147, Creativity in Education: Teaching for Creativity Development

Hughes,J. and Panel David, 2018, p.549-569, Leadership, creativity, and innovation: A critical review

Jiang Qiu, John D Medaglia, Qunlin Chen, Richard FBetzel, Rog E Beaty, SharonLThompson -Schill,, Yoed N Kenett , 2020, pp.3-24, The effect of semantic memory degeneration on creative thinking: A voxel-based morphometry analysis

Mohnen, A., \& Ostermaier, A. (2013). Incentives for creativity: Limits of objective performance evaluation.

Kupers, Panel Elisa, 2020, p.1-7, Creativity in interaction: the dynamics of teacher-student interactions during a musical composition task

Kupers, Panel Elisa, 2020, pp.1-7, Creativity in interaction: the dynamics of teacher-student interactions during a musical composition task

Lucas, Bill, 2019, pp.11-25, Lucas (2019) Teaching and assessing creativity in schools in England

Mohnen, A., \& Ostermaier, A. (2013). Incentives for creativity: Limits of objective performance evaluation. 